\title{
Do I consider a career in dental academia and if so how do I go about it?
}

\author{
Charlotte Schofield, ${ }^{* 1}$ Matthew Johnston ${ }^{1}$ and Paul Blaylock²
}

\section{Key points}

Highlights the lack of existing academic opportunities at the beginning of a dental career.
Shows the benefits of integrating research into early career roles, using a scheme in the North East as an example.
Reinforces the need for more early academic opportunities within dentistry, echoing the findings of the Advancing Dental Care review.

\begin{abstract}
Medicine has around 450 academic foundation roles available every year involving research and teaching, leadership and management, or quality improvement. However, an academic career in dentistry is not as clearly defined immediately post-graduation. The North East General Professional Training scheme is a two-year longitudinal dental foundation training scheme and this year, for the first time, has conducted a pilot programme allowing two trainees the opportunity to complete a research project. The experiences of the two trainees confirm the benefit of dental foundation research posts and support the need for additional positions nationally.
\end{abstract}

\section{Introduction}

\section{How do I pursue a career in dental} academia?

This is a question which doesn't have an easy answer. Medicine has around 450 academic foundation roles available every year involving research and teaching, leadership and management, or quality improvement. ${ }^{1}$ This Academic Foundation Programme (AFP) enables foundation doctors to develop their clinical skills while having dedicated time set aside for academic activities. ${ }^{2}$ However, an academic career in dentistry is not as clearly defined immediately post-graduation. There is no clear academic pathway, nor are there numerous training roles available upon graduation. As a result, research and academia

${ }^{1}$ Newcastle Dental Hospital, Newcastle upon Tyne NHS Foundation Trust, Richardson Road, Newcastle upon Tyne NE2 4AZ, UK; ${ }^{2}$ Health Education England, Bourne House, Mandale Business Park, Durham, Tyne and Wear, DH1

1TH, UK.

*Correspondence to: Charlotte Schofield

Email address: charlotte.e.schofield@gmail.com

Refereed Paper.

Accepted 5 May 2020

https://doi.org/10.1038/s41415-020-1991-y may not be considered as a career option or properly understood by undergraduates and newly qualified dentists. Indeed, one of the recommendations from Advancing Dental Care (ADC) was to commission a task force to review models of training to develop a dental academia workforce strategy in both the dental schools and primary care. ${ }^{3}$

Recent articles have further corroborated this, with current trainees discussing some of the limited availability of research within dental core trainee positions, while promoting the roles they do. ${ }^{4,5}$ However, without more structured options for an early academic pathway, this option is not open for many new trainees who otherwise would be suited to such roles, and they may not even be aware that this is a pathway open to them.

The North East General Professional Training (GPT) scheme is a two-year longitudinal dental foundation training (DFT) scheme, ${ }^{6,7}$ encompassing DFT and DCT1 where the trainees alternate weekly between a week in general practice and a week in Newcastle Dental Hospital. As this scheme encompasses both DFT and hospital dentistry, it allows a transition into the hospital role while gaining and developing general dentistry skills in practice life. A pilot programme has been launched within it this year, giving two general professional training trainees (GPTTs) the opportunity to undertake a specific research placement for the second year of the programme. The two-year scheme is something which has already been assessed in the ADC project as having advantages over the one-year DFT programme. Working within both hospital and practice settings simultaneously allows for an informed career choice $^{8}$ and the added benefit of the pilot research roles has now further extended this choice into academia and research.

During the first year of the scheme, two research positions were made available through application. The successful applicants were then given the choice between four research programmes to become involved in, depending on their interests and future career goals. As the programme was running for half a day a week in both hospital and practice for one year, it made sense to become involved in an existing project to improve the potential for successful outputs by the end of the year. The following details the experiences to date of the two current GPTTs undertaking the research pilot. 


\section{Charlotte Schofield}

The DIAMOND project ${ }^{9}$ being undertaken at Newcastle University is looking at the current system of allocation of resources on a national level to primary dental services, with a view to developing new formulae to address oral health inequalities. My role within this has been to analyse both the Adult Dental Health Survey (ADHS) and the Children's Dental Health Survey (CDHS) through regression methods to determine where oral health inequalities exist. I chose this project because it was something which was looking to have a national output and the potential impact of the project therefore appealed to me. It was also a completely new type of research for me and I wanted a project which would develop my skills. I also personally have an interest in children's oral health; therefore, being able to look at the oral health inequalities within the CDHS attracted me. Statistical analysis won't be everyone's cup of tea, although it is something I have enjoyed and this is just one part of what the research role has entailed.

The programme has also involved attendance at Newcastle University's Annual Clinical Academic Pathway Event. This was an opportunity to listen to the pathways available in medicine and dentistry, and the different routes people have taken in their careers. I also attended a meeting of The International Centre for Oral Health Inequalities Research and Policy ${ }^{6}$ at University College London, where I was able to listen to presentations about other work being undertaken around oral health inequalities.

A key output from my perspective is to produce a publication, an area which is currently ongoing and means I am developing my research writing skills. Other aims included a presentation to the dental hospital and a poster at a conference. However, due to COVID-19, these two goals are now a longerterm aspiration, although very much still a goal. Both the processes and the outputs from the project will also contribute to my portfolio for future DCT applications.

Through this role, I have been able to develop a wide range of skills working alongside the project team and have had access to researchers who are eminent in their fields, something which has been both daunting and exciting. It has been possible to see what research and an academic role entail. It can sit within a career in dentistry, making it rewarding and interesting, knowing that you can potentially make a difference to the future of dentistry. I have been able to gain an understanding of the processes involved in setting up a research project and it has allowed me to formulate my own idea for a research topic in the future, with additional knowledge of the processes required to undertake this. The programme has also consolidated in my mind that I want to continue to pursue an academic element of my future career.

\section{Matthew Johnston}

The research pilot scheme has been the perfect opportunity to initiate and develop my future career in dental research. Prior to the last few years, research seemed a far and distant aspect of dentistry and I was unsure how this fitted in with a career in clinical dentistry - something I wouldn't want to lose touch with. Knowing people doing medical AFPs, the concept had always been interesting but, for a dentist, unachievable.

My project - a dental education-based study - involved the planning, delivery and validation of the Caries Café. ${ }^{10}$ This event was introduced at Newcastle Dental School in 2016, when I myself was a third-year student. It aims to draw together the knowledge surrounding dental caries that has been gained in a multitude of courses throughout the curriculum.

My role as the project lead involved the application for project approval, creation and delivery of multiple questionnaires and focus groups, and statistical analysis of the collected data. The ultimate aim of the project was to inform the future planning of teaching methods such as the Caries Café and also to construct a similar educational resource for our oral dental health sciences students.

Prior to COVID-19, the project was on track and initial analysis of the data showed promise. Our second run of the questionnaire has had to be delayed with the lockdown of the university, but we are hoping to pick up the project again to produce more meaningful data, allowing for continual analysis and development of the Caries Café.

Similarly, a publication and presentation at an international conference, which were one of the goals for this project, has been put on hold for now.

The research pilot scheme has been an invaluable experience, highlighting the options available within dental research. It has allowed me to develop my planning, research, analytical and journal-writing skillset, by working alongside a team of talented and experienced researchers. It has also allowed me to become involved in other projects and groups I would otherwise not have been exposed to: clinical academic events, collaborative research with other universities and early career researcher conferences.

The role itself hasn't completely flipped my future career on its head - I still don't want to be a full-time academic. I will always want to be a clinical dentist; however, I have now seen how clinical dentistry and academia can work alongside each other, to provide not only a varied and diverse career, but one that can have a long-term impact on dentistry in the UK, be it through dental education or otherwise.

\section{Other projects}

The GPT scheme has also allowed other trainees on the programme to become involved in research projects. Two others are currently involved in reviewing the provision of advanced restorative dentistry, putting together and collating a survey which has been sent out to GDPs. ${ }^{11}$ This project is being run by the Northern Dental Practice Based Research Network, who hold regular meetings in North East England and have various projects that GDPs can become involved in how to join the network and current projects can be found on their website. ${ }^{12}$ This is a great option for those who wish to pursue a career in practice while maintaining an interest in research.

\section{Conclusion}

If you have a project that you want to pursue or feel that research is something that interests you, there are roles and options available. The importance of research within early dental training is beginning to gain further momentum; however, it is currently minimal and on a regional basis. Dentistry would benefit from a structured academic foundation programme, similar to that in medicine, to allow future dentists to structure their academic career early on along with supporting the future of dental education.

\section{References}

1. UK Foundation Programme. Academic Foundation Programme. Available at https://foundationprogramme nhs.uk/programmes/2-year-foundation-programme/ academic-training/ (accessed April 2020). 
2. The UK Foundation Programme. Rough Guide to the Academic Foundation Programme. 2013. Available at https://foundationprogramme.nhs.uk/wp-content/ uploads/sites/2/2019/11/Rough-Guide-to-theAcademic-Foundation-Programme.pdf (accessed April 2020).

3. Health Education England. Advancing Dental Care Available at https://www.hee.nhs.uk/our-work advancing-dental-care (accessed April 2020).

4. Whitehouse L. Dental academics: Our future denta academics. Br Dent J 2019; 226: 162.

5. Shelswell, J, Patel V. How can DCTs become involved in research? BrDent J 2020; 228: 325-326.

6. Karsondas, N, Karsondas, N, Blaylock P. The two-year longitudinal dental foundation training programme: an option worth revisiting. Br Dent J 2019; 226: 224-227.

7. COPDEND. A Reference Guide for Dental Foundation Training in England, Wales and Northern Ireland. 2016. Available at https://www.copdend.org/ wp-content/uploads/2018/03/Blue-Guide-2016.pdf (accessed April 2020).

8. University College London. Dental Public Health. Available online at https://www.ucl.ac.uk/ epidemiology-health-care/research/eph/research/ dental-public-health (accessed April 2020).

9. Newcastle University. School of Dental Sciences staff profile: Dr. Chris Vernazza. Available at https://www. ncl.ac.uk/dental/staff/profile/christophervernazza. html\#research (accessed April 2020)
10. Taylor G, Wakeling L A, Freeman Z. Caries Café for Paediatric Dentistry. Br Soc Paediatr Dent 2018; DOI: $10.13140 /$ RG.2.2.24423.29604. Available online at https://www.researchgate.net/ publication/329585932_Caries_Cafe_for_Paediatric Dentistry (accessed April 2020)

11. Northern Dental Practice Based Research Network. Restorative Dentistry Referrals - GDPs Views. Available online at https://blogs.ncl.ac.uk/ northerndentres/currentprojects/restorativedentistry-referrals-gdp-views/ (accessed April 2020)

12. Northern Dental Practice Based Research Network Homepage. Available online at https://blogs.ncl. ac.uk/northerndentres/ (accessed April 2020). 